\title{
Zona Franca de Manaus: instabilidade do modelo e alternativas para o aproveitamento de seu real potencial
}

\author{
Manaus Free Zone: Model instability and alternatives for the use of its reais potential
}

Zona Franca de Manaus: Inestabilidad modelo y alternativas para el uso de su potencial real

Recebido: 29/08/2021 | Revisado: 04/09/2021 | Aceito: 06/09/2021 | Publicado: 08/09/2021

\author{
Iris Rodrigues Queiroz \\ ORCID: https://orcid.org/0000-0001-8952-7949 \\ Centro Universitário Fametro, Brasil \\ E-mail: íris.queiroz.acs@gmail.com \\ Claudenira Alves da Silva \\ ORCID: https://orcid.org/0000-0001-8820-6852 \\ Centro Universitário Fametro, Brasil \\ E-mail: claudenira.asn@hotmail.com \\ Jean Serrão de Oliveira \\ ORCID: https://orcid.org/0000-0001-8671-9793 \\ Universidad de León, Espanha \\ jeanserrao@hotmail.com
}

\begin{abstract}
Resumo
Em 1957, foi criado o modelo de desenvolvimento econômico para o estado do Amazonas denominado Zona Franca de Manaus (ZFM) por meio da 3.173/57, que posteriormente foi revogada pelo Decreto-Lei 288/63. Como, constitucionalmente, a ZFM não pode ser deslocada para outro lugar, mas nada impede que seja implantado um modelo semelhante em outras regiões do país ou seja alterado os tributos que são concedidos ao modelo o objetivo geral da pesquisa é propor alternativas para os entraves enfrentado pelo modelo ZFM que está deixando de se fortalecer frente a burocracia do governo federal e estadual. Para o desenvolvimento da pesquisa foi necessário realizar um estudo bibliográfico para o embasamento teórico da ZFM, incentivos fiscais, Processo Produtivo Básico (PPB) e Pesquisa, Desenvolvimento e Inovação (PD\&I), além da pesquisa em campo para ter um suporte técnico e especializado para elaborar as propostas aos entraves enfrentados pelo modelo ZFM. Ao final da pesquisa conclui-se que os objetivos foram alcançados porque foi proposto alternativas para a melhor aplicação do modelo, entre as sugestões do estudo há: garantir que não se emitam normas infraconstitucionais que firam a constituição, ou seja, garantir à ZFM sua existência com vantagens competitivas e comparativas até o ano de 2073; revisar todos os marcos regulatórios para concessão de área, aprovação do projeto e acompanhamento industrial; demostrar aos ministérios da economia a dinâmica econômica produzida na ZFM cria impedância financeira, entre outras.
\end{abstract}

Palavras-chave: Zona Franca de Manaus; Desenvolvimento regional; Potenciais econômicos.

\begin{abstract}
In 1957, the economic development model was created for the state of Amazonas called Manaus Free Trade Zone (ZFM) through 3.173/57, which was later repealed by Decree-Law 288/63. As, constitutionally, the ZFM cannot be moved elsewhere, but nothing prevents the deposition of a similar model in other regions of the country or changes the taxes that are granted to the model the general objective of the research is to propose alternatives to the obstacles faced by the ZFM model that is failing to strengthen itself in the face of bureaucracy of the federal and state government. For the development of the research it was necessary to conduct a bibliographic study for the theoretical basis of the ZFM, tax incentives, Basic Productive Process (PPB) and Research, Development and Innovation (PD\&I), in addition to field research to have a technical and specialized support to elaborate the proposals to the obstacles faced by the ZFM model. At the end of the research it is concluded that the objectives were achieved because alternatives were proposed for the better application of the model, among the suggestions of the study there are: to ensure that infraconstitutional norms are not emitted, that is, to guarantee the ZFM its existence with competitive and comparative advantages until the year 2073; review all regulatory frameworks for area concession, project approval and industrial monitoring; to show the ministries of the economy the economic dynamics produced in the ZFM creates financial impedance, among others.
\end{abstract}

Keywords: Manaus Free Trade Zone; Regional development; Economic potentials.

\section{Resumen}

En 1957, se creó el modelo de desarrollo económico para el estado de Amazonas llamado Zona franca de Manaos (ZFM) a través de 3.173/57, que luego fue derogado por el Decreto-Ley 288/63. Como, constitucionalmente, la ZFM 
no puede ser trasladada a otro lugar, pero nada impide la deposición de un modelo similar en otras regiones del país o cambia los impuestos que se otorgan al modelo el objetivo general de la investigación es proponer alternativas a los obstáculos que enfrenta el modelo ZFM que no logra fortalecerse frente a la burocracia del gobierno federal y estatal. Para el desarrollo de la investigación fue necesario realizar un estudio bibliográfico para las bases teóricas de la ZFM, incentivos fiscales, Proceso Productivo Básico (PPB) e Investigación, Desarrollo e Innovación (PD\&I), además de investigación de campo para contar con un soporte técnico y especializado para elaborar las propuestas a los obstáculos que enfrenta el modelo ZFM. Al final de la investigación se concluye que los objetivos se alcanzaron porque se propusieron alternativas para la mejor aplicación del modelo, entre las sugerencias del estudio se encuentran: asegurar que no se cumplan las normas infraconstitucionales, es decir, garantizar a la ZFM su existencia con ventajas competitivas y comparativas hasta el año 2073; revisar todos los marcos regulatorios para la concesión de áreas, la aprobación de proyectos y el monitoreo industrial; mostrar a los ministerios de economía la dinámica económica producida en la ZFM crea impedancia financiera, entre otros.

Palabras clave: Zona Franca de Manaus; Desarrollo regional; Potencialidades económicas.

\section{Introdução}

É papel do governo proporcionar melhores condições para o crescimento econômico de determinada região com menor índice de crescimento econômico. Nessa perspectiva, em 1921, depois do declínio do ciclo da borracha que Manaus vivenciou, nesse período, um registro de 2.500 casas abandonadas, ou seja, grande parte da população imigrou para outros estados brasileiros. Por esse fator, em 1957, ainda no governo Juscelino Kubitschek (JK), entrou em vigor a Lei $\mathrm{n}^{\mathrm{o}} 3.173 / 57$ com intuito de promover a integração da Amazônia para o cenário nacional o que alavancou o crescimento econômico e social passando de 100 mil habitantes para 280 mil (Pellegrino, 2015).

Desde então, Manaus desfruta de políticas de incentivos fiscais característicos e próprios, diferentes do resto do país, que estimulam a produção nessa região, fazendo com que as empresas fiquem instaladas para oferecer a oportunidade para a região, gerando emprego, crescimento econômico e desenvolvimento local.

Segundo o documento da Superintendência da Zona Fraca de Manaus (SUFRAMA): Indicadores de Desempenho do Polo Industrial de Manaus (PIM), atualizado em 21/03/2019, o PIM tem registrado mais de 600 empresas que desfrutam de incentivos fiscais, empregam mais de 100 mil pessoas de forma direta e outros 400 mil de forma indireta, e em 2018 faturou mais de R\$92.676,00, portanto, a Zona Franca de Manaus (ZFM) pode ser considerada um dos principais polos econômicos da região.

Apesar de sabermos que o modelo ZFM durante o período de instalação em 1957 até o atual ano obteve êxito na sua finalidade que é atrair empresas, promover ocupação e integração territorial com outras regiões do país, gerar emprego e renda, além de aumentar o Produto Interno Bruto (PIB) per capita da região norte, o modelo vem sendo motivo de constantes debates e negociações entre as bancadas políticas o que gera instabilidade ao modelo.

Como, constitucionalmente, a ZFM não pode ser deslocada para outro lugar, mas nada impede que seja implantado um modelo semelhante em outras regiões do país ou seja alterado os tributos que são concedidos ao modelo esta pesquisa tem a seguinte questão problema a ser respondida: quais as ações que podem ser realizadas para a ter o melhor aproveitamento do Modelo ZFM?

Para responder à questão problema, essa pesquisa possui o seguinte objetivo geral: propor alternativas para os entraves enfrentado pelo modelo ZFM que está deixando de se fortalecer frente a burocracia do governo federal e estadual. Com os conseguintes objetivos específicos: transcrever a história e as legislações referente ao modelo ZFM; explanar sobre os principais entraves enfrentado pelo modelo ZFM; e propor alternativas para o aproveitamento do real potencial do modelo.

Para o desenvolvimento da pesquisa foi necessário realizar um estudo bibliográfico para o embasamento teórico da ZFM, incentivos fiscais, Processo Produtivo Básico (PPB) e Pesquisa, Desenvolvimento E Inovação (PD\&I), além da pesquisa em campo para ter um suporte técnico e especializado para elaborar as propostas aos entraves enfrentados pelo modelo ZFM. 


\section{Referencial Teórico}

\subsection{Zona Franca De Manaus (ZFM)}

Após a crise da borracha, período que ocorreu a grade depressão econômica na região norte, em 1957, foi criado o modelo de desenvolvimento econômico para o estado do Amazonas denominado ZFM por meio da 3.173/57, que posteriormente foi revogada pelo Decreto-Lei 288/63.

Com o modelo ZFM o governo brasileiro pretendia garantir o abastecimento do mercado doméstico de bens de consumo duráveis, anteriormente importados, por meio da utilização de insumos e bens de capital produzidos pelas indústrias do Sul do país. Onde, o governo brasileiro respondeu com uma política de importação favorável à aquisição no mercado internacional de mercadorias destinada à indústria e ao comercio local (Torres, 2014).

Segundo a Superintendência da SUFRAMA (2014), a ZFM é constituída, no seu aspecto histórico, de cinco fases, senão vejamos:

a) Primeira fase ocorreu entre 1967 até 1975 , onde existia extrema atividade comercial, com auto fluxo turístico que facilitava a promoção da exportação dos produtos é o polo se concentrava na administração de entradas e estocagem de mercadorias;

b) Segunda fase ocorreu entre 1975 até 1990 , onde o modelo passou por formulação por meio dos Decreto-Lei n 1435 de 1975 e 1455 de 1976 estipulando índice de produtos nacionalizados e nacionais gerando mais de 80 mil empregos diretos com um faturamento de US\$ 8,4 bilhões;

c) Terceira fase ocorreu entre 1991 até 1996 marcada pela institucionalizado dos incentivos fiscais, consequentemente promovendo o crescimento econômico nacional e a normatização do Processo Produtivo Básico (PPB), ampliando também os municípios as zonas de livres comercio;

d) Quarta fase ocorreu entre 1996 até 2002 tendo como marco o incentivo da competitividade por meio do uso da tecnologia, bem como a criação do centro de desenvolvimento tecnológico

e) Fase atual entra em vigor a nova Lei de Informática que anunciou os incentivos fiscais, promovendo competividade pela tecnologia e soluções estratégias do Processo Produtivo Básico.

O modelo ZFM é uma iniciativa política brasileira que tem sua abrangência (Figura 1) às margens do Rio Negro e Amazonas nos municípios de Manaus, Itacoatiara e Rio Preto da Eva, no Estado do Amazonas, incentivos diferenciados para proporcionar ao estado crescimento econômico reduzindo a desigualdade regional (Barbosa et al, 2013).

Figura 1 - Decreto Lei 288/67 - Área De 10.000 Km2/ Territorialidade.

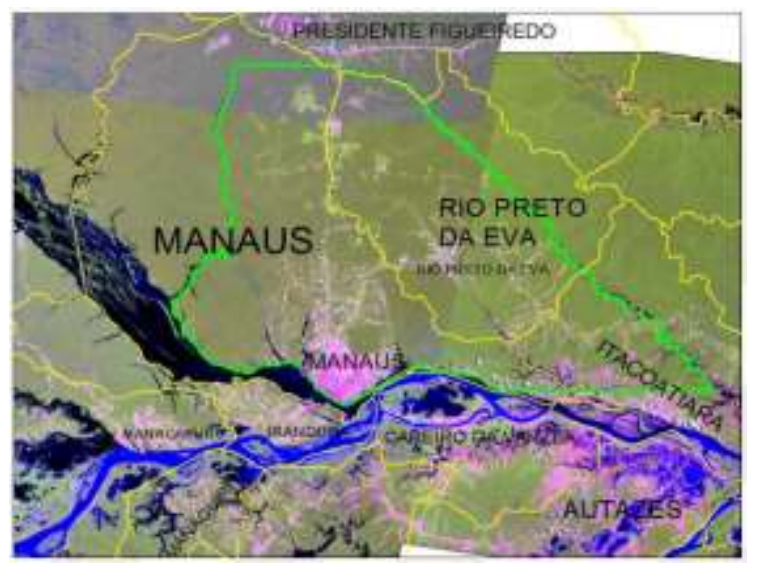

Fonte: DAS (2015). 


\subsection{Incentivos fiscais}

Os incentivos fiscais são atrativos ao investimento de particulares para promover uma ação pretendida pelo Poder Público. Nessa ação o Estado se caracteriza mais pela concessão de prêmio e menos pela condição de estado sancionador. Diferencia-se do incentivo financeiro porque exige o investimento prévio pelo empresário e o prêmio é uma redução na tributação (Martins et al, 2019).

Júnior e Rey (2019) explicam que os incentivos fiscais são concedidos por duas Autarquias Federais como a Superintendência da Zona Fraca de Manaus (SUFRAMA), Superintendência do Desenvolvimento da Amazônia (SUDAM) e pelo próprio Governo do Estado com a Secretaria de Estado de Planejamento, Desenvolvimento, Ciência, Tecnologia e Inovação (Seplan-CTI), e o autor explica quais os principais incentivos concedidos por esses órgãos:

- Suframa: administra a concessão de redução de até $88 \%$ do Imposto de Importação (II) sobre os insumos destinados à industrialização, a isenção do Imposto sobre Produtos Industrializados (IPI), a isenção da contribuição para o Programa de Integração Social (PIS), Programa de Formação do Patrimônio do Servidor Público (PASEP) e da Contribuição para o Financiamento da Seguridade Social (COFINS) nas operações internas na ZFM e os benefícios e contrapartidas referentes à Lei de Informática da ZFM;

- Seplan-CTI: concede a redução de 55 a 100\% sobre o Imposto sobre Operações relativas à Circulação de Mercadorias e Serviços de Transporte Interestadual e Intermunicipal e de Comunicação (ICMS) para empresas constituídas no PIM, e

- Sudam: administra a concessão da redução de $75 \%$ do Imposto de Renda de Pessoa Jurídica (IRPJ).

Para as empresas receberem esses benefícios fiscais, que reduzem consideravelmente o seu custo de produção elas devem realizar contrapartidas que benefício o estado e a população, entre estas temos a geração de emprego para a população, reinvestimento de lucro na região, concessão de benefícios sociais aos trabalhadores (como pagamento de previdência social, alimentação, assistência à saúde, educação, entre outras), investimento na formação e capacitação de recursos humanos para o desenvolvimento científico e tecnológico, bem como investimento em

Pesquisa, Desenvolvimento e Inovação (PD\&I), realização de Projeto Produtivo Basicão (PPB), entre outros (SUFRAMA, 2019).

Desde sua criação, até os dias atuais, o faturamento da ZFM, mesmo com as dificuldades econômicas, apresenta bons resultados, o que é favorável para regiões que tem sua economia muito dependente das empresas que estão instaladas na ZFM porque são beneficiados com incentivos fiscais.

\subsection{Processo Produtivo Básico (PPB)}

O PPB é conceituado pelo Art. 7, § 8., letra "b" como um conjunto mínimo de operações, no estabelecimento fabril, que caracteriza a efetiva industrialização de determinado produto. (Alínea incluída pela Lei no 8.387, de 30.12.91).

Segundo o site da SUFRAMA (2017), o PPB regulamenta os procedimentos fabris para a industrialização dos produtos dentro da ZFM, em contrapartida a concedidos as indústrias os benefícios fiscais. A autarquia federal responsável pela administração e fiscalização do PPB é a SUFRAMA. Sendo, a Coordenação Geral de Acompanhamento de Projetos Industriais (CGAPI) que acompanha o projeto aprovados.

O Quadro 1 apresenta os resultados e indicadores do acompanhamento dos projetos industriais comparados à respectiva série histórica, segundo dados da SUFRAMA. 
Quadro 1 - Resultados e Indicadores do Acompanhamento dos Projetos Industriais comparados à respectiva série histórica.

\begin{tabular}{|c|c|c|c|c|}
\hline DADOS GERAIS MACROECONÔMICOS & 2013 & 2014 & 2015 & 2016 \\
\hline Empresas com projeto aprovado & 1.023 & 1.056 & 1.083 & 1.107 \\
\hline Empresas Acompanhadas (Somente empresas com pelo menos 1 produto não cancelado) & 612 & 571 & 624 & 531 \\
\hline Empresas em Operação (Informaram produção ou tiveram LO/LP emitido no último ano) & 494 & 490 & 481 & 456 \\
\hline Produtos Acompanhados (Somente empresas com pelo menos 1 produto não cancelado) & 2.195 & 1.929 & 1.895 & 1.845 \\
\hline Projetos Acompanhados (Somente empresas com pelo menos 1 produto não cancelado) & 1.310 & 1.308 & 1.282 & 1.275 \\
\hline
\end{tabular}

Fonte: SUFRAMA (2017).

No quadro acima e possível perceber que desde o seu vigor os resultados e indicadores do acompanhamento dos projetos industriais comparados à respectiva série histórica observa-se uma gradativa crescente submissão de projetos industriais. Então, a apesar de muitas vezes ser considerado um processo burocrático dispendioso, a busca por tal garantia legal e constante conforme vemos na tabela demostrada porque as industriam buscam a ZFM como meio de reduzir seus custos tributários.

\subsection{Pesquisa, Desenvolvimento e Inovação (PD\&I)}

Para a estimular Pesquisa, Desenvolvimento e Inovação (PD\&I) no Brasil, entrou em vigor a Lei de Informática que beneficia as empresas com exoneração e/ou suspensão do imposto sobre IPI (da ordem de 15\% para a maioria dos produtos incentivados) e II, em contrapartida as empresas devem realizar investimento de 5\% do seu faturamento bruto em PD\&I, bem com cumprir as etapas mínimas do PPB a serem realizadas no Brasil.

A Lei de informática da ZFM permite que as industrias usufrua dos benefícios fiscais citados acima, no entanto, diferentes das outras região do país, as empresas situadas na ZFM que desfrutam dos incentivos fiscais possui uma Lei diferenciada, que trata-se da Lei n. 8.387, de 30 de dezembro de 1991, que nada mais é do que uma contrapartida necessária para usufruto dos incentivos fiscais, com o proposito e subsidiar que as indústrias de eletrônicos de Manaus apresentaram capacidade de absorção tecnológica (Prochnik et al, 2015).

Costa et al (2018) aponta que esse dispositivo legal dispõe que as indústrias de bens de informática que pretendem utilizar os benefícios fiscais da ZFM devem aplicar anualmente no mínimo 2,3\% do faturamento bruto no mercado interno em atividades de pesquisa e desenvolvimento na Amazônia contratando instituições ou depositando no Fundo Nacional de Desenvolvimento Científico e Tecnológico (FNDCT-CT) Amazônia além do mínimo de 0,5\%. Outros 2,7 \% do faturamento bruto as empresas devem investir em PD\&I na Amazônia com possibilidade aplicar no ambiente interno à empresa.

Portanto, a Lei de Informática é capaz de promover uma maior competitividade dos produtos nacionais frente aos importados uma vez que as empresas incorporam tecnologias de produtos e de processos de produção compatíveis com o estado da arte, além de promover aproximação entre firmas e instituições para atividades de PD\&I (Cavalcante et al, 2017).

\section{Metodologia}

Esta pesquisa, quanto aos objetivos, pode ser classificada como descritiva e explicativa, pois, propor alternativas para os entraves enfrentado pelo modelo ZFM que está deixando de se fortalecer frente a burocracia do governo federal e estadual. Para Brocke, Rosemann (2013), os estudos descritivos buscam especificar as propriedades, as características ou qualquer outro fenômeno que submeta a uma análise, ou seja, pretende unicamente coletar informações sobre os conceitos que se refere o assunto. 
Quanto aos procedimentos, trata-se de uma pesquisa bibliográfico e documental com fonte primária e secundaria. Lopes (2006, p.220), conceitua a pesquisa como aquela "realizada com base na documentação direta [...] ou indireta (resultando de execução de produtos oriundos de publicações oficiais ou privadas encontradas nos arquivos". Onde, a base de dados forma plataformas acadêmicas, sites especializados, legislações pertinentes além da utilização de livros.

Além disso foi realizado uma pesquisa em campo, para buscar apoio e entrevistar o atual coordenador-geral de estudos econômicos e empresariais da Superintendência da Zona Franca de Manaus (SUFRAMA), Marcelo Souza Pereira.

Para responder à questão da pesquisa foi necessário realizar uma análise do atual cenário econômico e político que o Modelo ZFM está enquadrado, então foi elaborado uma planilha que trata dos entraves que o modelo enfrenta para que possa ser utilizado em pleno funcionamento e consiga fortalecer e desenvolver a região norte do Brasil. Dada essa tratativa, a abordagem da pesquisa é qualitativa. Na visão de Oliveira (2004, p. 116) o tratamento qualitativo de um problema é utilizado para entender a relação de causa e efeito do fenômeno consequentemente chegar a sua verdade, razão ou solução.

\section{Resultados e Discussão}

O Quadro 2 aponta os principais entraves enfrentado pela ZFM que está deixando de se fortalecer frente a burocracia do governo federal e as barreias políticas o que atrapalham o desenvolvimento da região. Para potencializar o modelo é proposto alterativas que irão explorar o modelo ZFM dando mais vantagens a região a se desenvolver e crescer.

Para Miranda (2013), as vulnerabilidades da ZFM têm como ponto crítico sua continuada dependência à concessão de incentivos fiscais. Este padrão de dependência é frágil, pois sempre podem surgir crises e novos desdobramentos na condução da política econômica.

Desse modo, o Quadro 2 foi organizado da seguinte forma: entraves enfrentados pelo modelo ZFM; propostas para as barreiras que devem dar mais força a ZFM; quem são os responsáveis em pôr em prática as propostas apontas; qual a urgência da implementação das propostas; e como as propostas podem ser realizadas para ter o aproveitamento de seu real potencial do modelo ZFM. 
Quadro 2 - Entraves e os tratamento para potencializar o aproveitamento do Modelo ZFM.

\begin{tabular}{|c|c|c|c|c|c|}
\hline $\mathbf{N}$ & ENTRAVES & PROPOSTAS & QUEM? & QUANDO? & COMO? \\
\hline 1 & $\begin{array}{l}\text { Recursos provenientes da } \\
\text { ZFM são repassados a } \\
\text { Brasília }\end{array}$ & $\begin{array}{c}\text { Conceder maior } \\
\text { autonomia (administrativa } \\
\text { e financeira) à } \\
\text { SUFRAMA } \\
\end{array}$ & $\begin{array}{l}\text { Ministério da } \\
\text { Economia }\end{array}$ & Imediatamente & $\begin{array}{c}\text { Alterar a estrutura dos } \\
\text { ministérios da Economia dando } \\
\text { autonomia à Suframa (aplicando } \\
\text { o conceito jurídico de autarquia. }\end{array}$ \\
\hline 2 & $\begin{array}{c}\text { Centralização do Ministério } \\
\text { da economia e pastas } \\
\text { subsequentes e mecanismos } \\
\text { de papelocracia na própria } \\
\text { Suframa } \\
\end{array}$ & $\begin{array}{c}\text { Descentralizar os recursos } \\
\text { de PD\&I }\end{array}$ & $\begin{array}{l}\text { Ministério da } \\
\text { Economia/ } \\
\text { Suframa }\end{array}$ & Imediatamente & $\begin{array}{l}\text { Suframa e ministério, via } \\
\text { CAPDA devem aprovar }\end{array}$ \\
\hline 3 & $\begin{array}{c}\text { Divergências Políticas, } \\
\text { interesses de empresários e } \\
\text { órgãos públicos }\end{array}$ & $\begin{array}{c}\text { Garantir que as normas } \\
\text { constitucionais sejam } \\
\text { obedecidas }\end{array}$ & $\begin{array}{l}\text { Ministério da } \\
\text { Economia }\end{array}$ & Imediatamente & $\begin{array}{c}\text { Garantir que não se emitam } \\
\text { normas infraconstitucionais que } \\
\text { firam a constituição, ou seja, } \\
\text { garantir à ZFM sua existência } \\
\text { com vantagens competitivas e } \\
\text { comparativas até o ano de } 2073\end{array}$ \\
\hline 4 & $\begin{array}{l}\text { Recursos financeiros e } \\
\text { burocracia dos estados } \\
\text { governados por classes } \\
\text { políticas ideológicas }\end{array}$ & $\begin{array}{l}\text { Difundir o modelo nos } 5 \\
\text { estados (propagar) }\end{array}$ & $\begin{array}{c}\text { Suframa }+ \\
\text { ARARA }\end{array}$ & Imediatamente & $\begin{array}{l}\text { Criação da comissão permanente } \\
\text { pelo conselho administrativo da } \\
\text { Suframa para difundir o modelo } \\
\text { nos } 5 \text { estados junto à classe } \\
\text { política, empresarial, judiciário e } \\
\text { sociedade civil organizada. }\end{array}$ \\
\hline 5 & $\begin{array}{l}\text { Burocracia excessiva, pouco } \\
\text { interesse nos processos }\end{array}$ & $\begin{array}{l}\text { Desburocratizar a gestão } \\
\text { (acompanhamento) do } \\
\text { incentivo }\end{array}$ & Suframa & Imediatamente & $\begin{array}{l}\text { Revisar todos os marcos } \\
\text { regulatórios para concessão de } \\
\text { área, aprovação do projeto e } \\
\text { acompanhamento industrial (PPB } \\
\text { e PD\&I). }\end{array}$ \\
\hline 6 & $\begin{array}{c}\text { Interesse s econômico } \\
\text { estadual }\end{array}$ & $\begin{array}{l}\text { Garantir orçamento para } \\
\text { investimento nas } \\
\text { atividades finalísticas do } \\
\text { Modelo ZFM (Resolução } \\
\text { 72/2016 - CAS). }\end{array}$ & $\begin{array}{l}\text { Ministério da } \\
\text { Economia }\end{array}$ & Imediatamente & $\begin{array}{c}\text { Junto aos ministérios da } \\
\text { economia, demostrara que a } \\
\text { dinâmica econômica produzida } \\
\text { na ZFM cria impedância } \\
\text { financeira, pois gera arrecadação } \\
\text { desta forma, priorizar que o } \\
\text { orçamento inscrito seja } \\
\text { totalmente utilizado nos } \\
\text { investimentos nos } 5 \text { estados } \\
\text { (resolução } 72 / 2016 \text { - CAS). }\end{array}$ \\
\hline 7 & $\begin{array}{l}\text { A Suframa e estado não } \\
\text { possuiu nenhum tipo de } \\
\text { programa semelhante. }\end{array}$ & $\begin{array}{l}\text { Atrair plantas industrial } \\
\text { de seguimentos } \\
\text { alternativos (Plano de } \\
\text { atração de investimento) }\end{array}$ & $\begin{array}{l}\text { Suframa/ } \\
\text { Ministério/ } \\
\text { Estados }\end{array}$ & Imediatamente & $\begin{array}{l}\text { Criar excursão aos países árabe, } \\
\text { china, estados unidos e Europa a } \\
\text { fim de atrair investidores. }\end{array}$ \\
\hline 8 & $\begin{array}{c}\text { Os principais setores } \\
\text { explorados e que possuem } \\
\text { maior faturamento na ZFM e } \\
\text { o polo duas rodas e o } \\
\text { eletroeletrônico }\end{array}$ & $\begin{array}{c}\text { Diversificar os vetores de } \\
\text { desenvolvimento regional } \\
\text { para além da indústria } \\
\text { eletrônica }\end{array}$ & $\begin{array}{l}\text { Suframa/ } \\
\text { Ministério/ } \\
\text { Estados }\end{array}$ & Imediatamente & $\begin{array}{c}\text { Garantir a aplicação do PDI junto } \\
\text { ao governo do estado (ver quais } \\
\text { vetores quais os vetores } \\
\text { econômicos que sejam } \\
\text { desenvolver) }\end{array}$ \\
\hline
\end{tabular}

Fonte: Autores (2021).

\subsection{Pontos de instabilidade e alternativa para o aproveitamento do real potencial do modelo}

\subsubsection{Concedendo maior autonomia (administrativa e financeira) à SUFRAMA}

A SUFRAMA é uma autarquia federal que foi criada pelo Decreto-lei $\mathrm{n}^{\circ}$ 288/67, atrelada ao Ministério do Desenvolvimento, Indústria e Comércio Exterior (MDIC), possuindo sua sede na cidade de Manaus, onde, a autarquia tem a responsabilidade de identificar alternativas econômicas e atrair empreendimento para a região, objetivando a geração de emprego e renda.

Mediante aos debates políticos que tramitam no senado a respeito da reforma tributária proposta pelo atual ministro da economia o modelo ZFM vem enfrentando instabilidade, e cada vez mais a SUFRAMA vem perdendo espaço e autonomia para a tomada de decisões no que se refere a pautas voltadas para o desenvolvimento socioeconômico da região. A 
arbitrariedade está centralizada junto ao governo federal no ministério da economia, cada passo a ser seguido tem que passar pela pasta do governo, vide exemplo de empresas que tenha objetivo de se instalar para usufruir de benefícios fiscais.

Logo então se nos moldes anteriores a constituição de 88 quando a SUFRAMA realmente exercia autarquia e não dependia tanto da intermediação com a política e com a influência do governo federal nas suas decisões, como a exemplificar as discussões de temas do interesse de investidores ou a autorização de Processo Produtivo Básico (PPB) que licenciam a produção no âmbito da ZFM. Com a indicação do Coronel Alberto Menezes, o órgão parece caminhar agora para uma maior autonomia e independência na tomada de decisões, pois isso anteriormente foi deixado de lado pelo motivo do planejamento de governos anteriores ser voltado para o capitalismo progressista e não pelo Liberalismo.

\subsubsection{Difundindo o modelo nos 5 estados}

As Áreas de livre comercio (ALC's) que são compostas por municípios dos estados do Amazonas, Rondônia, Acre, Roraima, Amapá, que também são cordialmente conhecidas como (ARARA) pelo motivo das iniciais dos nomes, foram criadas mediante a Leis e regulamentadas posteriormente por decretos, com início e meios finais de desenvolver socioeconomicamente a região norte em comum todo.

Diante deste fato o que chama atenção é que tanto o modelo de ALC's, ZFM e Amazônia Ocidental (AMOC), são poucos divulgados, consequentemente suas histórias, Leis, regulamentações e alterações não são conhecidas diante da maior parte da população que é civilizada através dos seus incentivos. Difundir se torna mais que necessário, é uma questão imprescindível e de extrema urgência pelos motivos de apenas aplicar as regras do jogo aos envolvidos diretamente, ou seja, empresas, governo e órgãos regulamentadores, sem ao menos facilitar o conhecimento para os cidadãos indiretamente afetados.

Portanto uma ação imediata junto aos grandes centros de ensino privado e público, pode ter grande valia na questão da agregação e isso tem que ser integralizado conforme Quadro 3:

Quadro 3 - Ação imediata para propagação do modelo ZFM.

\begin{tabular}{|c|c|}
\hline Ensino médio 1 & História da ZFM \\
\hline Ensino médio 2 & Sistema fiscal da ZFM. \\
\hline Ensino médio 3 & Gestão dos tributos da ZFM (básico) \\
\hline Graduação/pós-graduação & Gestão dos tributos da ZFM (avançado) \\
\hline
\end{tabular}

Fonte: Autores (2021).

Isso originaria um princípio a longo prazo de conhecimento da ZFM, assim a população não seria tão leiga nesta temática, pois o fator ciência do modelo ZFM acrescentaria algo de relevante na tomada de decisões das pessoas, seja ela nas grandes escalas de eleições, bem como nas pequenas escalas de compreensão de incentivos básicos dos produtos.

\subsubsection{Desburocratizando a gestão ZFM}

Com o passar dos tempos, desde a criação da ZFM, o mundo entrou numa dinâmica de constante mudanças pelo fator tecnológico ter interferido direta e indiretamente nos processos tangíveis e nos regulamentos intangíveis do modelo de desenvolvimento citado. Portando fica explicito que desde a sua regulamentação no Decreto-Lei 288/67, mesmo com o decorrer das mudanças durante sua trajetória, o órgão "SUFRAMA" vem perdendo cada vez mais espaço na tomada de decisões, por conta do intervencionismo estatal. 
De acordo com SUFRAMA, (2019, p. 186) ratifica a responsabilidade socioeconômica da SUFRAMA e da SUDAM com o desenvolvimento da Amazônia. Porque uma vez explicitada a metodologia de cálculos e apresentados exemplos práticos de operações para a determinação dos valores dos incentivos fiscais, os usuários ampliam a autonomia sem desvincular-se dos propósitos doutrinários e regulatórios do Modelo de Desenvolvimento Econômico da ZFM.

Portanto é fundamental e imprescindível, conceder essa autonomia, que por décadas é cada vez mais amarrada as mudanças de legislação e trocas subsequentes de governos. É preciso que tenha se em vista que, uma vez a lei outorgada, deve ser regida da maneira que foi feita, sem dar margem a interpretações para mudanças conforme o novo agente governamental é substituído, as regras do jogo de maneira alguma devem ser alteradas.

\subsubsection{Garantir orçamento para investimento nas atividades finalísticas do modelo ZFM}

Descentralizar o fomento de tecnologia e inovação e estratégia política de Tecnologia da Informação (TI), isso tem chamado atenção para o desenvolvimento da área de software, e empresas do setor aderem aos incentivos fiscais concedidos pela Lei do Bem, amparado no Decreto $\mathrm{n}^{\circ}$ 6.008/2006, que trata do benefício fiscal concedido às empresas produtoras de bens de informática na ZFM com investimentos direcionados para atividades de Pesquisa e Desenvolvimento na Amazônia.

Segundo site da SUFRAMA (2019) há um investimento estimados em R \$ 600 milhões que devem ser aplicado em programas prioritários na região de domínio da SUFRAMA desenvolver a região norte ,a Resolução nº 13, de Janeiro de 2016 Art. $1^{\circ}$ estabelecer os critérios e procedimentos administrativos para apresentação, analise, aprovação, liberação, dos recursos ,acompanhamento ,fiscalização e prestação de contas dos recursos aplicados no âmbito dos programas e projetos prioritários na área de atuação da Suframa. O Comitê das atividades de Pesquisa e Desenvolvimento na Amazônia (CAPDA) regulamenta quatro programas prioritários: Empreendedorismo Inovador, Bioeconomia, Recursos Humanos e Economia.

O Superintendente adjunto de Planejamento e Desenvolvimento Regional da SUFRAMA explica que dos programa prioritários aprovados pela CAPDA três deles possui instituições coordenadoras já o programa de Bioeconomia não possui, ainda está em processo de aprovação, com a descentralização e distribuir os recursos e essencial pra o desenvolvimento da região SUFRAMA e CAPDA devem aprovar regulamentos que priorizem os investimentos em pesquisas de produtos que resultem em vetores de desenvolvimento como Bioeconomia ,Mineração, Agropecuária, Pesca e energia .Ligar o programa prioritário como potencial que a região possui.

\subsubsection{Desburocratizar a gestão (acompanhamento) do incentivo}

O Brasil tem um grande potencial para desenvolver projetos de inovação tecnológica, porém, a burocracia para aprovar o financiamento de atividades de PD\&I e um dos maiores entravo que impossibilita o avanço tecnológico. Pois, as exigências dos órgãos públicos que controlam e fiscalizam os programas de desenvolvimento e pesquisas causa atrasos na realização de pesquisas.

Devido a contraposição entre inovação e burocracia acaba gerando transtorno e perda de tempo, maior parte tempo que deveria ser investido em pesquisas e desperdiçados com burocracia. Com tudo ocasiona o atraso econômico no Brasil, se não há pesquisas não haverá inovação. Diante dos fatos de desenvolvimento e pesquisas a gente entende que não consegue fazer o giro econômico, há necessidade de que haja a possibilidade de desenvolver mudanças, ser mais flexível em algumas legislações, análise e liberação do processo ser mais ágio, facilitando o desenvolvimento de todos, principalmente das micro e pequenas empresas.

No amazonas o prazo para SUFRAMA emitir o parecer seria de 30 a 60 dias, porém o plano PD\&I e encaminhado para o Concelho Administrativo da Suframa (CAS) para dar o parecer conclusivo se estende por anos. Para que ocorra o desenvolvimento no Amazonas e necessário que a os marcos regulatórios para concessão de área, aprovação do projeto e 
acompanhamento industrial (PPB e PD\&I) que a tutela o poder de aprovação seja dado a SUFRAMA. O processo burocrático será avaliado em tempo mais ágio juntamente com os projetos laboratoriais de pesquisas que devem se estender a microempresas e empresas de pequeno porte. Com estas facilidades atrair empresas, atrair negócios, construir um ambiente favorável que vai movimentar a economia da região norte.

\subsubsection{Garantir orçamento para investimento nas atividades finalísticas do modelo ZFM}

Em 1967 foi criado o um projeto para desenvolver a região amazônica com previsão de duração 30 anos e depois se esperaria que outras atividades se desenvolvessem. Os incentivos fiscais concedidos a ZFM, se mantém a custas de relações muito problemáticas o qual gera insegurança para as empresas instaladas e para novos investidores (SUFRAMA 2016).

Pode-se dizer que isso não se realizou por se tratar de um conjunto de interesses econômicos locais e estaduais. Dessa forma ao invés de expandir o que ocorreu foi concentrar tudo o que poderia ser distribuído no interior, para a capital. De modo que o PIM não foi suficiente para melhorar as condições de vida da maioria da população no Amazonas, porém seu potencial econômico desenvolvido e vasto. O setor industriário é um dos que mais emprega e movimenta a economia dentro da região norte. Já polo agropecuarista, desenvolve suas atividades na agricultura no ramo de madeiras, como a comercialização das variedades de madeira, e ao cultivo de peixes, e demais atividades

Diante dos fatos há possibilidades de que a partir da dinâmica econômica ZFM surjam outras atividades econômicas, porém e necessário que haja investimentos nas atividades finalísticas do modelo ZFM. conforme a Resolução 72/2016 "Dispõe sobre os critérios de reconhecimento da predominância e da preponderância das matérias-primas de origem regional para efeitos de fruição de isenção do IPI nas ALCs.

Desta forma, deve-se priorizar que o orçamento inscrito seja totalmente utilizado nos investimentos localizadas nos Municípios de Boa Vista e Bonfim, nos Estados de Roraima; Tabatinga, Amazonas; Guajará-Mirim, no de Rondônia; Macapá e Santana, Amapá; e, Brasiléia, com extensão para Epitaciolândia e Cruzeiro do Sul, no Estado do Acre. A ZFM não é o custo para o país e sim um porto econômico incluem uma série de elementos básicos para atrair empresas para região a fim de se gerar empregos e movimentar a economia.

\subsubsection{Atrair plantas industrial de seguimentos alternativos (plano de atração de investimento)}

A ZFM possui diversos setores produtivos, entre estes destacam-se: o eletroeletrônico, o polo industrial de duas rodas, termoplásticos, químico, metalúrgico e outros, contudo no gráfico 1 é possível observar que há setores que são mais bem explorados que outros. 
Gráfico 1 - Participação dos subsetores de atividade no faturamento do PIM - Jan a Dez/ 2018.

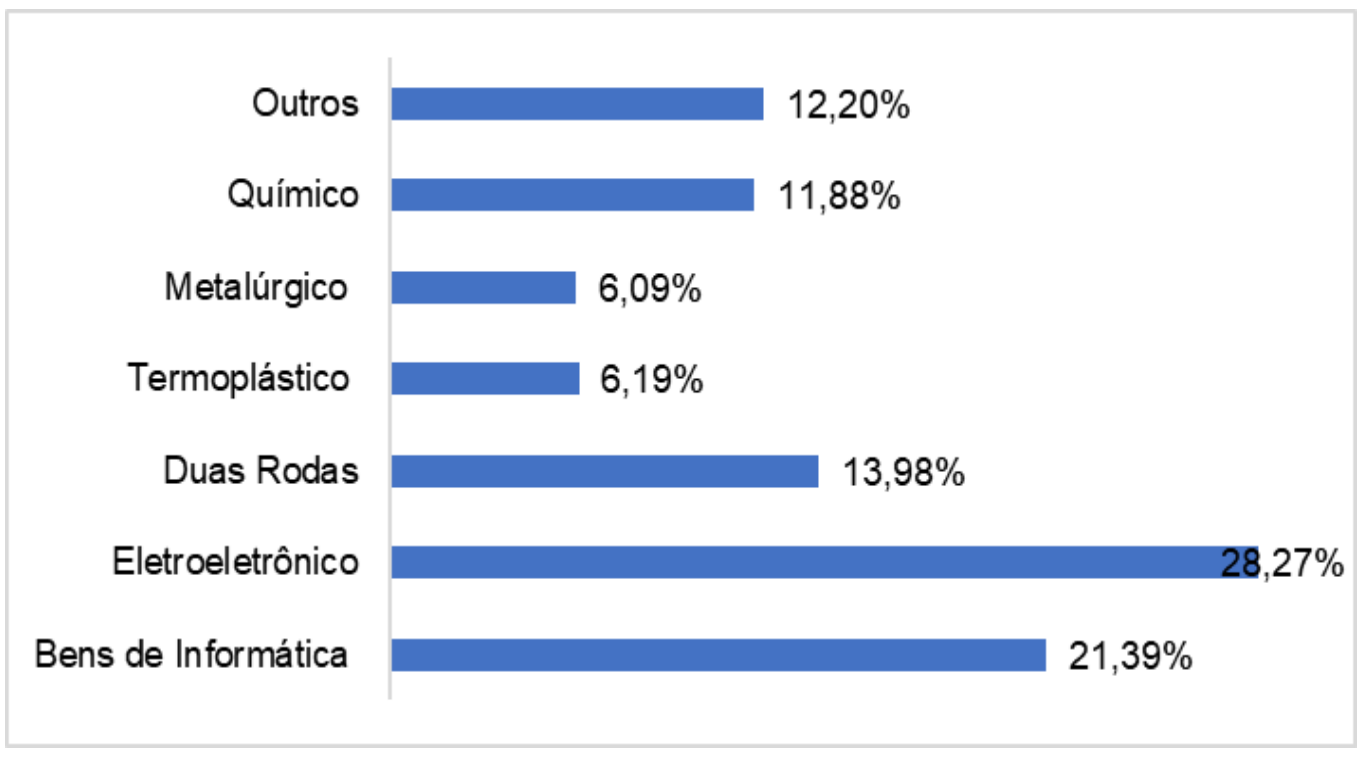

Fonte: SUFRAMA (2019).

A indústria da ZFM muitas vezes supera modelos industriais de outros países do mundo, como é o caso do polo duas rodas que produz a cada 20 segundo uma motocicleta, em comparação com Japão produz o mesmo produto a cada 46 segundos. Outro setor que é bem explorado é o eletro létrico, pois temos o maior centro de produção da América Latina (Pacífico, 2019).

Segundo Catela e Seabra (2017), o setor de eletroeletrônico da ZFM é fortemente dependente dos insumos provenientes de São Paulo, em especial dos setores de metalurgia, máquinas e equipamentos, refino de petróleo e outros químicos e fármacos. Portanto, compreende-se que o setor químico pode ser mais explorado na ZFM e deixar de ser dependente de outros países outras zonas industriais do Brasil.

Quando se prospecta novos segmentos para o setor industrial da ZFM pode-se pensar em alguns polos que podem ser bem explorados pela região. A SUFRAMA (2017) aponta os seguintes segmentos: gás-químico; petroquímico; fertilizantes; biodiversidade e energia solar.

Uma alternativa para buscar alternativas para aproveitar o melhor potencial da ZFM e fazer com que a modelo não depende de outros estados brasileiros e/ou países é criar excursão aos países árabe, china, estados unidos e Europa a fim de atrair investidores para demostrar como o PIM ainda é uma zona industrial que pode oferecer mais e melhores resultados econômicos do que tem atualmente.

\subsubsection{Diversificar os vetores de desenvolvimento regional para além da indústria eletrônica}

Com o forte debate político sobre mudança no regime tributário brasileiro e sobre o custo da ZFM para o país, o modelo regional tornou-se cada vez mais instável e fez com que os empresários não investirem no PIM. Pensando dessa forma, a Suframa em parceria com os ministério e Estado devem verificar outras possibilidades para que a depressão da borracha não leva a região ao declino econômico novamente.

O Plano Diretor industrial (PDI) ${ }^{1}$ são diretrizes táticas pertinentes aos polos econômicos da indústria, da agropecuária, ou seja, o plano agrupa estrutura produtiva administrada pela SUFRAMA que é o PI e o Distrito Agropecuário da SUFRAMA

${ }^{1}$ O Plano Diretor Industrial foi apresentado e aprovado pelo Conselho de Administração da SUFRAMA em sua $275^{\mathrm{a}}$ reunião ordinária, realizada em 26/08/2016. 
(DAS), a AMOC e as ALC não havendo distinções quanto às funções e às regulamentações para cada categoria desses entes para o período dos anos de 2017 a 2025 (Brasil, 2017).

A Figura 2 apresenta setores-chaves identificados no município de Manaus que podem ser melhor desenvolvidos.

Figura 2 - Setores-Chaves identificados.

\section{TRÁS}

\begin{tabular}{|c|}
\hline $\begin{array}{l}\text { - PROD. DE MADEIRA, EXCLUSIVE MÓVEIS } \\
\text { (Celulose p/ jornais, revistas, discos, papel em geral) }\end{array}$ \\
\hline $\begin{array}{l}\text { - PRODUTOS FARMACEUTICO } \\
\text { (Prod. Quimicos p/ Indus. Transformaçäo provenierte } \\
\text { da biodiversidade tecnológica) }\end{array}$ \\
\hline $\begin{array}{l}\text { - PERFUMARIA, HIGIENE E LIMPEZA } \\
\text { (Prod. Quimicos p/ Indus. Transformaçäo proveniente } \\
\text { da biodiver sidade tecnológica e Cosméticos) }\end{array}$ \\
\hline $\begin{array}{l}\text { - MATERIAIS DE ESCRITÓRIO E EQUIP. } \\
\text { DE INFORMÁTICA } \\
\text { (Bens de Informática, inclusive) }\end{array}$ \\
\hline $\begin{array}{l}\text { - ALIMENTOS E BEBIDAS } \\
\text { (Concentradosiengarrafamento extratos/bebidas } \\
\text { isotónicas, proteina animal p/alimentaçäo) }\end{array}$ \\
\hline $\begin{array}{l}\text { - OUTROS EQUIP. DE TRANSPORTE } \\
\text { (Duas rodas / naval) }\end{array}$ \\
\hline $\begin{array}{l}\text { - MATERIAIS ELETRÓNICO E EQUIP. } \\
\text { DE COMUNIC AÇÃOO } \\
\text { (Eletroelet ónico) }\end{array}$ \\
\hline $\begin{array}{l}\text { - TEXTIL } \\
\text { (Fibras: Juta / Malva / Carauá) }\end{array}$ \\
\hline $\begin{array}{l}\text { - AGRICULTURA, SILVICULTURA E } \\
\text { EXPLORA ÇÄO FLORESTAL } \\
\text { (Biomassa para utilizaçäo industrial) }\end{array}$ \\
\hline $\begin{array}{l}\text { - COMÉRCIO } \\
\text { (Compra de insumo nacional) }\end{array}$ \\
\hline $\begin{array}{l}\text { - ARTIGOS DE BORRACHA E PLÁ STICO } \\
\text { (Industria de transf. pneus, plasticos e afins) }\end{array}$ \\
\hline
\end{tabular}

\section{SETORES-CHAVES}

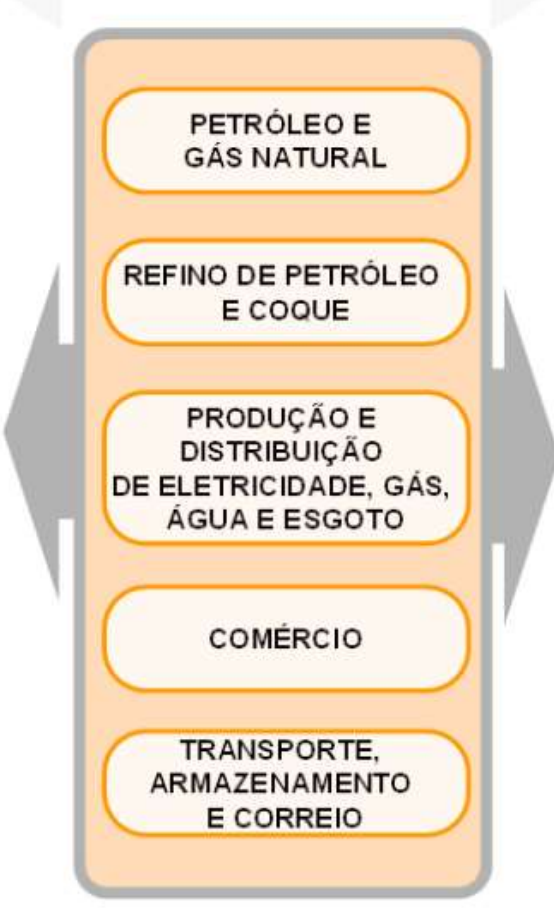

Fonte: Brasil (2017).

\section{FRENTE}

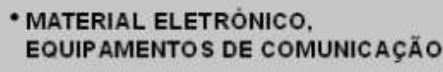

- AgRicultura, SILVICULtURA, EXPLORAÇÃo FLORESTAL

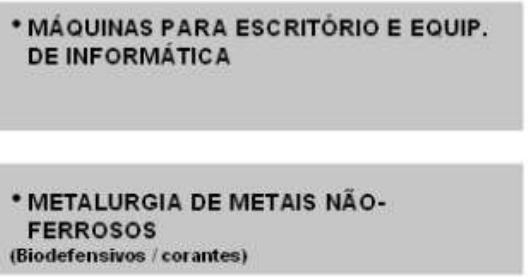

Então, o PDI elaborou instruções táticas para dinamizar a economia regional a partir do leque de incentivos extrafiscais na área de abrangência da ZFM, ao final foi apontado os setores chaves proposto na Figura 2.

Mas é importante frisar que dentre todas as atividades elencadas no setores-chaves do PDI têm como principal objetivo explorar as modalidades de incentivos extrafiscais concedidos a região norte, porém, seu diferencial está em preservar a sustentabilidade. Dentro do conceito de biodiversidade, caberia explicitar o direcionamento para fármacos, cosméticos ou alimentação (SUFRAMA, 2017).

A elaboração do PDI para os próximos anos tem exigido não apenas a reflexão técnica e política interna a autarquia, mas passa, doravante, a envolver o seu entorno institucional. Dada sua importância uma alternativa para aproveitar o potencial regional seria garantir que o PDI fosse aplicado de forma prática trazendo crescimento econômico para a região.

\section{Considerações Finais}

Essa pesquisa teve como objetivo propor alternativas para os entraves enfrentado pelo modelo ZFM que está deixando de se fortalecer frente a burocracia do governo federal e estadual, e para alcançar esse intuito foi necessário fazer uma pesquisa sobre as legislações pertinentes aos incentivos fiscais e o modelo de desenvolvimento econômico instalado na região, além de realizar uma entrevista informal com o coordenador-geral de estudos econômicos e empresariais da SUFRAMA.

Com a pesquisa pode-se verificar que os objetivos foram alcançados porque transcreveu-se a história e as legislações referente ao modelo ZFM, que teve seu início no declino da borracha para incentivar o crescimento econômico por meio da 
concessão de benefícios fiscais nas empresas que se instalassem na região norte. Hoje, o modelo pode ser considerado efetivo pois durantes esses anos trouxe emprego e renda para polução, bem como o desenvolvimento principalmente para área onde encontra-se o PIM.

Além do que, explanou-se sobre os principais entraves enfrentado pelo modelo ZFM que são: os recursos provenientes da ZFM são repassados a Brasília e não investido de forma direta na região, os principais setores explorados e que possuem maior faturamento na ZFM e o polo duas rodas e o eletroeletrônico, porém a região tem outras alternativas econômicas O PDI elaborado pela SUFRAMA e junto ao governo do estado não são aplicados de forma efetiva, entre outros.

Devido aos entreves da ZFM apontados na pesquisa que são barreiras para o aproveitamento do real potencial regional foi possível propor alternativas para a melhor aplicação do modelo, entre as sugestões do estudo há: garantir que não se emitam normas infraconstitucionais que firam a constituição, ou seja, garantir à ZFM sua existência com vantagens competitivas e comparativas até o ano de 2073; revisar todos os marcos regulatórios para concessão de área, aprovação do projeto e acompanhamento industrial; demostrar aos ministérios da economia a dinâmica econômica produzida na ZFM cria impedância financeira, pois gera arrecadação desta forma, priorizar que o orçamento inscrito seja totalmente utilizado nos investimentos nos 5 estados, entre outras.

Para estudo futuros sugere a realização de novas pesquisa para explanar com mais profundamente sobre cada entrave apontado na pesquisa, pois poderá ocorrer um embasamento e uma discussão maior sobre o porquê das barreiras e como podem ser tratadas para dar a região mais oportunidades econômicas, a sugestão apontada pode ser realizada e devem ser consideras para colocar ao modelo sempre em foco nos debates econômicos e políticos.

\section{Referências}

Barbosa, E. B. (2013). Zona Franca de Manaus: política brasileira de desenvolvimento socioeconômico regional. En Observatório de la Economía Latinoamricana, (184).

Brasil (2017) Superintendência da Zona Franca de Manaus. Plano diretor industrial: diretrizes táticas para a área de atuação da Suframa (2017-2025) Coordenação: Ana Maria Oliveira de Souza. SUFRAMA

Brasil (1991). Legislação Federal. Lei de Informática - Zona Franca de Manaus. Lei n. 8.387, de 30 de dezembro de 1991.

Brasil (1991) Legislação Federal. Processo Produtivo Básico (PPB). Lei Nº 8.387, De 30 De Dezembro De 1991

Brasil (1967). Legislação Federal. Zona Franca de Manaus. Decreto-Lei N²88 de 28 de fevereiro de 1967

Brocke, J. V., \& Rosemann, M. (2013). Metodologia de pesquisa. AMGH Editora

Catela, E. Y. S., \& Seabra, F. (2017). Productive agglomeration and transport modal choice: a case study of São Paulo and Manaus industrial sector. Nova Economia, 27, 295-321.

Cavalcante, M. C. V. (2017). Pesquisa e desenvolvimento como ferramenta das políticas públicas nacionais de ciência e tecnologia: Um estudo de caso da eficiência da Lei de Informática na Zona Franca de Manaus por meio da análise envoltória de dados. Universidade Federal Do Amazonas Faculdade De Tecnologia Programa De Pós-Graduação Em Engenharia De Produção.

Costa, A. R. R., Júnior, A. K., Barbosa, N. M., Sbragia, R., \& de Souza Marques, N. (2018). Análise dos Entraves e Facilitadores no Processo de Obtenção de Recursos para P\&D na Amazônia Ocidental. Amazon Business Research, (1), 40-57.

Júnior, J. C. P. C., \& Rey, K. M. M. (2019). A Zona Franca de Manaus pós Constituição Federal de 1988: 30 anos de desafios para a reinvenção do modelo de desenvolvimento da Amazônia. Ciência \& Trópico, 43(especial).

Pacífico, K. A. (2019. Zona Franca de Manaus: aspectos econômicos e tributários. Universidade Do Extremo Sul Catarinense - Unesc Curso De Administração - Linha De Formação Específica Em Comércio Exterior

LOPES, J. (2006). O fazer do trabalho científico em ciências sociais aplicadas. Ed. Universitária da UFPE.

Martins, R. S., Siegler, J., Souza-Junior, A., Flynn, B., \& Martins, G. S. (2019). Rede Global ou Local? Entendendo como Incentivos em Zonas de Livre Comércio Impactam a Configuração de Redes de Suprimentos. Revista de Administração Contemporânea, 23(5), 654-671.

Miranda, R. N. (2013). Zona Franca de Manaus: desafios e vulnerabilidades. Criado pelo Ato da Comissão Diretora n ${ }^{\circ} 10$, de 2011 , o Núcleo de Estudos e Pesquisas do Senado Federal.

Oliveira, S. L. (2004). Tratado de metodologia científica: projetos de pesquisas, TGI, TCC, monografias, dissertações e teses. (2a ed.), Pioneira. 
Research, Society and Development, v. 10, n. 11, e528101119985, 2021

(CC BY 4.0) | ISSN 2525-3409 | DOI: http://dx.doi.org/10.33448/rsd-v10i11.19985

Panorama do Distrito Agropecuário da Suframa (DAS). (2015). Coordenação de Ana Maria Oliveira de Souza e Renato Mendes Freitas. SUFRAMA.

Prochnik, V., Labrunie, M. L., Silveira, M. A., \& Ribeiro, E. P. (2015). A política da política industrial: o caso da Lei de Informática. Revista Brasileira de Inovação, 14, 133-152.

Pellegrino, L. N. (2015). A Zona Franca de Manaus sob a perspectiva do desenvolvimento histórico-econômico da Amazônia brasileira ocidental (2002-2014). Universidade Estadual Paulista

SUFRAMA (2014). Superintendia da Zona Franca de Manaus. História da Zona Franca de Manaus http://www.suframa.gov.br/zfm_historia.cfm.

SUFRAMA (2019). Contrapartidas exigidas. http://www.suframa.gov.br/invest/zona-franca-de-manaus-contrapartida.cfm.

SUFRAMA (2017). Superintendia da Zona Franca de Manaus. Processo Produtivo Básico. http://site.suframa.gov.br/assuntos/processos-produtivos-basicos

SUFRAMA (2018). Superintendia da Zona Franca de Manaus. Zona Franca de Manaus: Indicadores de desempenho do Polo Industrial de Manaus (2013 2018). http://site.suframa.gov.br/assuntos/modelo-zona-franca-de-manaus/INDICADORES_DEFINITIVO_DEZ2018.pdf .

SUFRAMA (2018). Superintendia da Zona Franca de Manaus. Zona Franca de Manaus: Indicadores de desempenho do Polo Industrial de Manaus (2013 2018). http://site.suframa.gov.br/assuntos/modelo-zona-franca-de-manaus/INDICADORES_DEFINITIVO_DEZ2018.pdf .

Torres, S. (2001). Raízes e rumos: perspectivas interdisciplinares em estudos americanos. 7Letras. 